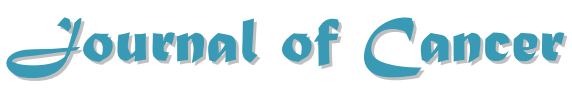

$2011 ; 2: 142-152$

Research Paper

(C) Ivyspring International Publisher. All rights reserved

\title{
An Eifective Personalized Approach to a Rare Tumor: Prolonged Survival in Metastatic Pancreatic Acinar Cell Carcinoma Based on Genetic Analysis and Cell Line Development
}

\section{Matthew D. Armstrong 1, Daniel Von Hoff 5, Bruce Barber 2, Laura A. Marlow ${ }^{3}$, Christina von Roemeling ${ }^{3}$, Simon J. Cooper ${ }^{3}$, Patrick Travis ${ }^{6}$, Elizabeth Campbell5, Ricardo Paz-Fumagalli4, John A. Copland ${ }^{3}$, Gerardo Colon-Otero ${ }^{1 凶}$}

1. Division of Hematology/Oncology;

2. Department of Laboratory Medicine and Pathology;

3. Department of Cancer Biology;

4. Department of Diagnostic Radiology, Mayo Clinic, Jacksonville, Florida, USA;

5. The Translational Genomics Research Institute (TGen), Phoenix AZ, USA;

6. Highlands Oncology Group, Bentonville AR, USA.

Corresponding author: Dr. Gerardo Colon-Otero, Division of Hematology/Oncology, Mayo Clinic, Jacksonville, Florida, 32224. gcolonotero@mayo.edu

Received: 2011.01.12; Accepted: 2011.02.23; Published: 2011.03.08

\begin{abstract}
Acinar cell carcinoma of the pancreas is an uncommon malignancy, accounting for less than $1 \%$ of all pancreatic neoplasms. Because of its rarity, only a few retrospective studies are available to help guide management. We report the case of a patient with metastatic ACC who achieved prolonged survival as a result of personalized treatment designed in part on the basis of molecular and in-vitro data collected on analysis of the tumor and a cell line developed from the liver metastasis. To our knowledge, this represents the first human cell line of ACC. The molecular findings on this case and this patient's cell line may be of use in the management of future cases of this rare tumor and allow the identification of potential novel targets for the effective treatment of this disease.
\end{abstract}

Key words: acinar cell pancreatic cancer, prolonged survival, personalized medicine, cell line

\section{Introduction}

Although the most common cells in the pancreas are the acinar cells, malignant transformation of these cells is very rare. Pancreatic adenocarcinomas, derived from epithelial cells lining the pancreatic ducts are the most common pancreatic malignancy followed by neuroendocrine tumors, with acinar cell carcinomas (ACC) of the pancreas representing less than $1 \%$ of all pancreatic tumors ${ }^{1-8}$. Fewer than 50 cases of ACC are diagnosed annually in the USA ${ }^{8}$. Patients with ACC are more likely to present at a younger age and with earlier stage tumors as compared to patients with the more common and deadlier pancreatic adenocarcinomas. ACC affects males more commonly than females ${ }^{1-8}$.

There are also significant differences in the clinical presentation of ACC as compared to pancreatic adenocarcinoma. Contrary to pancreatic adenocarcinoma cases, patients with early stage ACC frequently present with abdominal pain and bloating as the dominant symptoms. Occasionally, ACC tumors produce excessive lipase causing systemic fat necrosis-16. Clinical manifestations of this syndrome of fat 
necrosis can include panniculitis, discrete skin lesions and subcutaneous nodules. Pathologic fractures related to intraosseus necrosis have been described as well. Laboratory abnormalities include elevated serum lipase levels, eosinophilia, and occasionally elevated serum alpha fetoprotein levels.

Because of the rarity of this malignancy, studies have primarily consisted of retrospective chart reviews and case reports. Very limited data are available about effective systemic treatments for patients with recurrent, unresectable or metastatic disease. The rarity of the disease has thus far precluded systematic approach to treatment through clinical trials, and only a handful of retrospective reviews and case reports describing empiric treatments have been published ${ }^{1-8 \text {, }}$ 17-26.

We report a case of acinar cell carcinoma in which the patient had extended survival with metastatic disease. We attribute his extended survival to an aggressive multi-disciplinary approach involving a variety of localized and systemic treatments. Moreover, systemic treatments were guided by molecular and phenotypic studies performed on the patient's tumor tissue biopsies and derivative cell lines. This multi-disciplinary approach with translational studies offers a potential strategy for management of acinar cell carcinomas in particular and rare malignancies in general.

\section{Materials and Methods}

\section{Serum Chemistries}

Peripheral blood studies were monitored, including serum lipase, alpha fetoprotein, alkaline phosphatase, and CEA levels. Normal references range levels are as follows for serum lipase (7-60 $\mathrm{IU} / \mathrm{L})$, alpha fetoprotein $(0.0-5.9 \mathrm{ng} / \mathrm{ml})$, alkaline phosphatase (45 - $115 \mathrm{IU} / \mathrm{L})$ and CEA $(0-3.0 \mathrm{ng} / \mathrm{ml}$ for non-smoker).

\section{Biopsies and Immunhistochemistry}

Since ACC is a rare cancer with no standard of care, biopsies were requested by the patient for the purpose of establishing cell lines for therapeutic drug testing as well as RNA and protein analysis. IRB permission was obtained for this procedure. Biopsies were performed using needle biopsies. For needle biopsies, two to three 18-gauge needle core biopsies were performed. For DNA MA analysis, tissue was immediately frozen and shipped on dry ice to a central Clinical Laboratory Improvement Amendmentscertified laboratory (Caris Life Sciences, Phoenix, AZ). For immunohistochemistry (IHC), paraffin blocks were shipped on cold packs. For IHC studies, the formalin-fixed paraffin-embedded tumor samples had sections submitted and processed for standard IHC. IHC was performed for Her2/neu, estrogen receptor, progesterone receptor, c-kit, epidermal growth factor receptor (EGFR) and cyclooxygenase 2 (COX2) ERCC1 (DNA excision repair protein), p-glycoprotein, dihydrofolate reductase (DHFR), TYMS, secreted protein acidic cysteine-rich (SPARC, osteonectin), platelet derived growth factor (PDGFR) and topoisomerase II alpha (TOP2A). IHC was performed by Caris Life Science (Phoenix, AR). Human epidermal growth factor receptor 2 (HER2) and epidermal growth factor receptor (EGFR) were stained as specified by the vendor (DAKO, Copenhagen, Denmark). All other antibodies were purchased from commercial sources and visualized with a DAB biotin-free polymer detection kit. Appropriate positive control tissue was used for each antibody. Negative control slides were stained by replacing the primary antibody with an appropriately matched isotype-negative control reagent. All slides were counterstained with hematoxylin as the final step and cover slipped. All slides were evaluated semiquantitatively on a scale of 0 (no staining) to $4+$ and by the percentage of the tumor cells showing the reactivity by a single pathologist. IHC was considered positive for target if staining was $2+$ in $30 \%$ of cells.

\section{Gene Expression Analysis Using DNA Microarrays}

The frozen tumor fragments for microarray (MA) were placed in a glass tube on $0.5 \mathrm{~mL}$ of frozen $0.5 \mathrm{M}$ guanidine isothiocyanate solution and thawed and homogenized with a Covaris S2 (Covari, Woburn, MA). TriZol (0.5 mL) was added and mixed, and the solution was heated to $65^{\circ} \mathrm{C}$ for 5 minutes and then cooled on ice and phase separated by adding chloroform and centrifugation. An equal volume of $70 \%$ ethanol was added to the aqueous phase, which was chromatographed on a Qiagen Rneasy column (Qiagen, Germantown, MD). RNA was bound and then eluted. RNA was tested for integrity by assessing the ratio of $28 \mathrm{~S}$ to $18 \mathrm{~S}$ ribosomal RNA on an Agilent BioAnalyzer (Agilent, Santa Clara, CA). Tumor RNA and RNA from a sample of a normal pancreas were converted to cDNA and labeled during T7 polymerase amplification with contrasting fluor tagged (Cy3, Cy5) cytidine triphosphate. The labeled tumor and its tissue of origin reference were hybridized to an $\mathrm{Ag}$ ilent HIAv2 60-mer oligo array chip with 17,085 unique probes. Hybridization signals were acquired and normalized using Agilent's Feature Extraction software (version 7.1). The MA was considered positive for a target if the difference in expression for a gene between tumor and control organ tissue was at a significance level of $p<0.05$. 


\section{Cell line and animal model development for acinar cell pancreatic cancer}

Since no standard of care exists for acinar cell pancreatic cancer, the patient requested a liver biopsy of the tumor to attempt to develop a cell line and test drug sensitivity. Two such procedures occurred, one in May 2005 and the other in May 2008. The procedure was performed under local anesthetic and ultrasound guidance after obtaining consent from the patient. Biopsied tissue was frozen in liquid nitrogen as well as transported to the laboratory in sterile media and tissue was prepared for cell culture. Half of the tissue was minced, washed in PBS (Cellgro, Herndon, VA) and cultured in DMEM medium (Cellgro) supplemented with $10 \%$ fetal bovine serum (Hyclone, Logan, UT), non - essential amino acids (Cellgro), and penicillin-streptomycin-amphotericin B (Cellgro) at $37^{\circ} \mathrm{C}$ in a humidified atmosphere with 5\% CO2. The biopsied tissue collected May 2005 grew in culture up to passage 16. These primary cells (PanJ1) were drug tested at passage 3. Panc- 4 cells were derived from a biopsy of a lymph node metastasis. These cells have been cultured up to passage 13 and used at passage 7 for drug testing.

The other half of the tissue was implanted subcutaneously into two anesthetized athymic nude mouse (Harlan Laboratories, Indianapolis, IN) under IACUC approved procedures in an attempt to grow humanized tumors. This in vivo model could then be used to test promising drugs identified in cell lines grown in culture. The biopsied tumor implanted from the 2005 did not result in tumor growth in mice while the biopsied tissues from May 2008 resulted in tumors.

\section{Proliferation assays}

For growth analysis, cells were plated on day 0 in 12-well plates (Midwest Scientific, St. Louis, MO) in triplicate at a concentration of $2 \times 10^{4}$ cells / well. On day 1 , cells were treated with one of the following drugs: etoposide (topoisomerse II inhibitor), cytosine arabinoside (antimetabolic agent), bortezomib (proteasome inhibitor), doxorubicin (topoisomerase II inhibitor), irinotecan (topoisomerase I inhibitor) and STI571 (imatinib, receptor tyrosine kinase inhibitor, gift from Novartis, Switzerland), lapatinib (EGFR/HER2 inhibitor, gift from GlaxoSmithKline, United Kingdom), CCI-779 (temsirolimus, mTOR inhibitor, gift from Wyeth Pfizer Pharmaceuticals, New York, New York) and ixabepilone (microtubule stabilizer, less susceptible to P-glycoprotein mediated multidrug resistance, gift from Bristol-Myers Squibb, New York, New York). All other drugs were purchased from Sigma-Aldrich (St. Louis, MO). On day 4, cells were collected and counted on a Coulter Particle Counter (Beckman, Brea, CA). The mean and standard deviation were calculated and plotted.

To determine synergy of combinatorial therapy, the concentration of each drug where $50 \%$ of growth is inhibited (IC50) is first determined by dose concentration curves. Combining the drugs at a constant ratio at, below and above their IC50 concentrations is used to determine whether their antiproliferative activity is synergistic, additive or antagonistic. Results from this assay were used to calculate a combination index $(\mathrm{CI})$ value using the software program CalcuSyn (BioSoft, Ferguson, MO). The CI equation in CalcuSyn is based on the multiple drug-effect equation of Chou and Talalay (27). CI values less than 1 indicate a synergistic effect while CI values above 1 are indicative of antagonism.

\section{Statistical Analysis}

Data are presented as the mean \pm SD and comparisons of treatment groups were analyzed by two-tailed equal variance Student's $t$ test. Data for comparison of multiple groups are presented as mean $\pm \mathrm{SD}$ and were analyzed by ANOVA. ${ }^{*} \mathrm{p}<0.05$ was considered statistically significant.

\section{Case Report}

A very active, athletic 61 year-old male with well controlled coronary artery disease presented in late 2001 with recurrent episodes of severe epigastric pain associated with elevation of his serum lipase levels. A clinical suspicion of chronic cholecystitis led to a laparoscopic cholecystectomy without clinical benefit. In April 2003, an endoscopic ultrasound showed minimal dilatation of the pancreatic and common bile ducts, and an endoscopic retrograde cholangiopancreatography (ERCP) with sphincterotomy was performed with unremarkable findings and with no additional benefit.

In September 2003, two years after his initial presentation, an MRI demonstrated a $1.5 \mathrm{~cm}$ lesion at the junction of the body and tail of the pancreas, as well as a $1 \mathrm{~cm}$ lesion in the hepatic dome. Repeat endoscopic ultrasound demonstrated an ill-defined hypoechoic area in the body of the pancreas, with a non-diagnostic fine needle aspiration.

In October 2003 the patient underwent exploratory laparotomy with distal pancreatectomy and splenectomy. Intraoperative ultrasound showed a 3 $\mathrm{cm}$ liver lesion. Final pathology revealed a $6.5 \mathrm{~cm}$ high grade acinar cell carcinoma of the pancreas. Relevant blood chemistries revealed highly elevated serum lipase prior to surgery (Table 1). Because of tumor involving the margin of resection, further resection 
was performed, with focal involvement noted. Subsequent fine needle aspiration of the liver lesion confirmed metastatic disease. As this was the sole metastatic site, the lesion was treated with radiofrequency ablation. Adjuvant treatment consisted of 3 cycles of gemcitabine $(800 \mathrm{mg} / \mathrm{m} 2)$ and cisplatin $(20 \mathrm{mg} / \mathrm{m} 2)$ followed by radiation ( $4500 \mathrm{cGy}$ ) to the pancreatic bed concomitantly with five weekly cycles of cisplatin (40 $\mathrm{mg} / \mathrm{m} 2)$, completed in March 2004.

Restaging evaluation on April 2004 showed two new liver lesions, which were treated with radiofrequency ablation. This was followed by 5 cycles of weekly paclitaxel $80 \mathrm{mg} / \mathrm{m}^{2}$ with thalidomide $100 \mathrm{mg}$ daily, completed on May 2004. Thalidomide was discontinued July 2004 due to the development of deep vein thrombosis. The patient did well until February 2005 when he developed new liver metastases. Capecitabine $1000 \mathrm{mg}$ orally twice daily for two out of every three weeks was initiated then. Serum lipase, CEA and alkaline phosphatase levels were monitored over this period and reflected active disease (Table 1).

In May 2005, biopsies of his stable liver lesions were performed for gene microarray and immunohistochemistry analysis to identify altered genes that are potential targets (Table 2). A number of gene targets were identified to be over-expressed or present in the patient's liver lesion that included carboxylesterase 2 (CES2), topoisomerase IIB (TOP2B), deoxycytidine kinase (DCK), and nuclear factor of kappa light polypeptide gene enhancer in B-cells inhibitor alpha (NFKBIA). Immunohistochemistry (IHC) for HER2/neu, estrogen receptor (ER), progesterone receptor (PR), c-kit, epidermal growth factor receptor (EGFR) and cyclooxygenase 2 (COX-2) demonstrated positivity only for c-kit (Table 2 ). From the same biopsy tissue used for genomic analysis, primary cells in culture were also developed for drug testing. From this list of genes, FDA approved drugs known to target the protein products of these genes (Table 2) were tested in the patient's cells derived from the metastatic liver lesion (Figure 1). These drugs included the following: STI-571 (C-kit tyrosine kinase inhibitor), bortezomib (proteosome inhibitor), doxorubicin, etoposide and cytosine arabinoside. Using drug doses physiologically relevant to humans demonstrated a strong inhibition of cell growth and cell death $(>70 \%$ inhibition) was identified for all but etoposide and cytosine arabinoside (Figure 1).

Table I. Serum Lipase, CEA, Alkaline Phosphatase levels linked to clinical events.

\begin{tabular}{|c|c|c|c|c|c|}
\hline Date & Event & $\begin{array}{l}\text { Lipase } \\
(\mathrm{u} / \mathrm{L})\end{array}$ & $\begin{array}{l}\text { CEA } \\
(\mathrm{ng} / \mathrm{ml})\end{array}$ & $\begin{array}{l}\text { Alpha feto- } \\
\text { protein } \\
\text { ng/ml }\end{array}$ & $\begin{array}{l}\text { Alk. Phos } \\
\text { (IU/L) }\end{array}$ \\
\hline Oct/2003 & Prior to pancreatectomy & 100 & $\mathrm{~N} / \mathrm{A}$ & $\mathrm{N} / \mathrm{A}$ & 121 \\
\hline Oct/2003 & Post pancreatectomy and RFA & 32 & N/A & 6.4 & 129 \\
\hline April 2004 & $\begin{array}{l}\text { Post Chemoradiation/Two new } \\
\text { liver mets. }\end{array}$ & & 0.6 & 14.2 & 101 \\
\hline April 2004 & Post radioablation of liver mets. & 13 & 0.5 & 8.7 & 121 \\
\hline August 2004 & Post paclitaxel/thalidomide & 12 & 0.5 & 7.0 & 116 \\
\hline Feb/2005 & $\begin{array}{l}\text { Two new liver } \\
\text { mets/Capecitabine initiated }\end{array}$ & & 1.2 & 8.2 & 130 \\
\hline August/2005 & $\begin{array}{l}\text { Capecitabine treatment discon- } \\
\text { tinued with worsening disease }\end{array}$ & & & 7.8 & 240 \\
\hline 2006 & Before doxorubicin & 2027 & 1.5 & & 374 \\
\hline 2006 & During doxorubicin & 90 & 3.2 & 5.8 & 190 \\
\hline 2007 & $\begin{array}{l}\text { Before intra-arterial brachy- } \\
\text { therapy with Sirspheres }\end{array}$ & 100 & 3.4 & 6.3 & 179 \\
\hline 2007 & $\begin{array}{l}\text { After intra-arterial brachy- } \\
\text { therapy with Sirspheres }\end{array}$ & 31 & 3.5 & 14.1 & 457 \\
\hline Jan 2008 & Before radiofrequency ablation & 75 & 3.4 & 13.2 & 382 \\
\hline Jan 2008 & $\begin{array}{l}\text { After radiofrequency abla- } \\
\text { tion/ before cryotherapy }\end{array}$ & 110 & 3.3 & 9.5 & 368 \\
\hline July 2008 & $\begin{array}{l}\text { progression of liver lesions and } \\
\text { development of mesenteric } \\
\text { lesions }\end{array}$ & 150 & 3.4 & 8.9 & 431 \\
\hline Nov 2008 & $\begin{array}{l}\text { Before external beam radiation } \\
\text { to a progressive liver lesion }\end{array}$ & 222 & 4.1 & 9.8 & 583 \\
\hline January 2009 & $\begin{array}{l}\text { hepatic and mesenteric disease } \\
\text { had worsened }\end{array}$ & 682 & & 7.4 & 609 \\
\hline
\end{tabular}


Table 2. May 2005: Upregulated genes, protein, and matching FDA approved drugs identified from liver biopsy of ACC tumor.

\begin{tabular}{lll}
\hline Gene & Fold Increase & Possible Interacting gene \\
\hline CES2 & 3.09 & Irinotecan (topoisomerase 1 inhibitor) \\
TOP2B & 2.77 & Etoposide, Doxorubicin, Doxil \\
NFKBIA & 2.50 & Bortezomib (proteosome inhibitor) \\
DCK & 2.14 & Cytarabine (antimetabolic agent) \\
& & \\
Protein & IHC Intensity/\% cells staining positive & Possible Interacting agent \\
c-kit & $+2 / 100 \%$ & Imatanib (tyrosine kinase inhibitor) \\
\hline
\end{tabular}
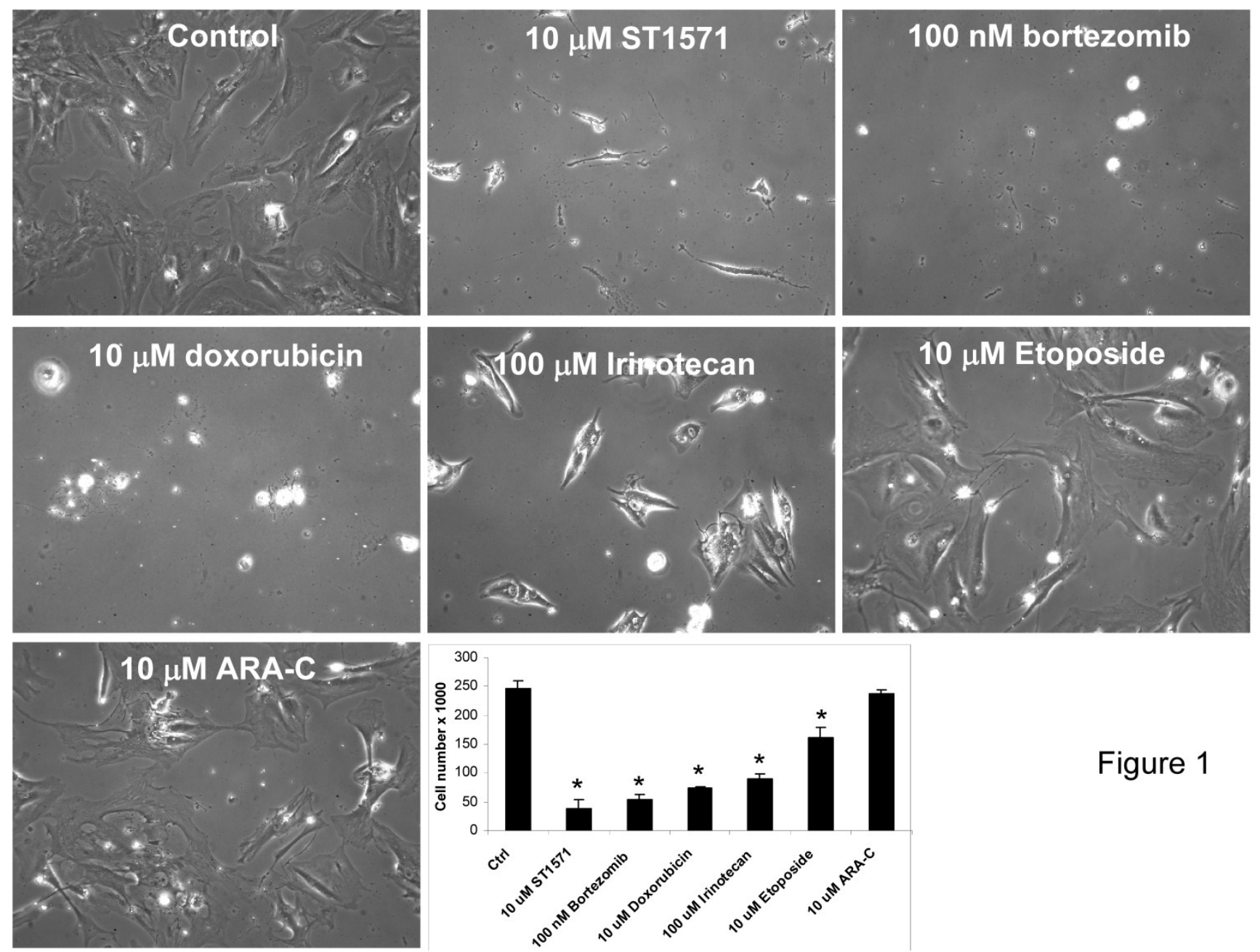

Figure 1

Figure I. Cell culture screening using FDA approved drugs which were identified from genomic profiling and IHC data showed inhibition of cell proliferation of patient's acinar cell pancreatic carcinoma cell line. Drugs were selected based upon gene array (Incyte) and immunohistochemistry data that identified druggable molecular targets present in the tumor known to be a molecular target for each drug. Cells established from a liver biopsy of the patient's tumor tissue were plated at $2 x$ $10^{4}$ cells $/ \mathrm{ml} /$ well on day 0 and treated with the indicated drugs and concentrations on day I. Media was changed every 48 hrs along with addition of new drugs. On day 6, cells were photographed at 20x magnification and counted using a Coulter Counter. Data are expressed as the mean and S.D. * indicates statistical difference from Control $(P<0.05)$. 
The liver lesions worsened in August 2005 and capecitabine was discontinued in favor of imatinib $400 \mathrm{mg}$ twice daily based on positive IHC for c-kit in the patient's biopsy tissue (Table 2). The patient had transient improvement in some of his lesions with this therapy but progressed by October 2005 with the development of skin lesions as well as worsened hepatic lesions. Imatinib was discontinued and etoposide 50 mg daily was initiated. Although after a month of therapy, the liver lesions improved, skin lesions progressed.

In view of the results from the patient's biopsy demonstrating elevated topoisomerase II mRNA (Table 2) and growth inhibition by doxorubicin (topoisomerase II inhibitor) in the patient's cell line (Figure 1), he was subsequently started on liposomal doxorubicin $\left(40 \mathrm{mg} / \mathrm{m}^{2}\right.$ every three weeks) through most of 2006 with excellent partial response (Figure 2). An index lesion in the liver was chosen and SUV on 10/18/05 averaged 6.4. One year later after the liposomal doxorubicin treatment, the SUV average decreased substantially to 2.1 .

After 16 cycles of this treatment, with no evidence of metastatic progression, the treatment was discontinued due to the potential for cardiac toxicity associated with cumulative doses of doxorubicin. Patient's cardiac function remained normal.

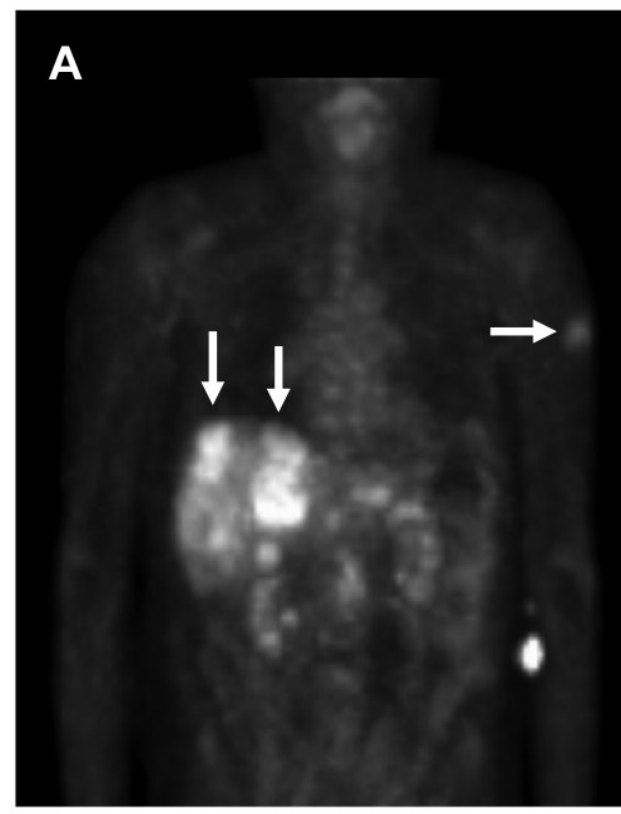

The patient then underwent hepatic intra-arterial brachytherapy with Sirspheres in February 2007. An isolated progressive liver lesion was treated with radiofrequency ablation in January 2008; this area was re-treated with cryotherapy in April 2008 due to residual disease. For these three procedures, lipase and relevant chemistries are shown in Table 1.

The patient received stereotactic radiosurgery to a pericardial lymph node in May 2008. However, prior to stereotactic radiosurgery, the patient requested another biopsy of the lymph node for the purpose of performing gene array analysis, immunohistochemistry and development of a new cell line for the purpose of identifying drug targets and potential therapeutic drugs. The thought was that the tumor had evolved into a more aggressive phenotype with underlying oncogenic changes in the genome and proteome. Biopsy yielded tissue for genomic and IHC analysis. IHC data now revealed positive staining for excision repair cross-complementing rodent repair deficiency, complementation group 1 (ERCC1), dihydrofolate reductase (DHFR), thymidylate synthetase (TYMS), PR, acidic cysteine-rich secreted protein (SPARC, osteonectin) Epidermal growth factor receptor (EGFR), platelet derived growth factor receptor (PDGFR) and topoisomerase (DNA) II alpha (TOP2A) (Table 3).

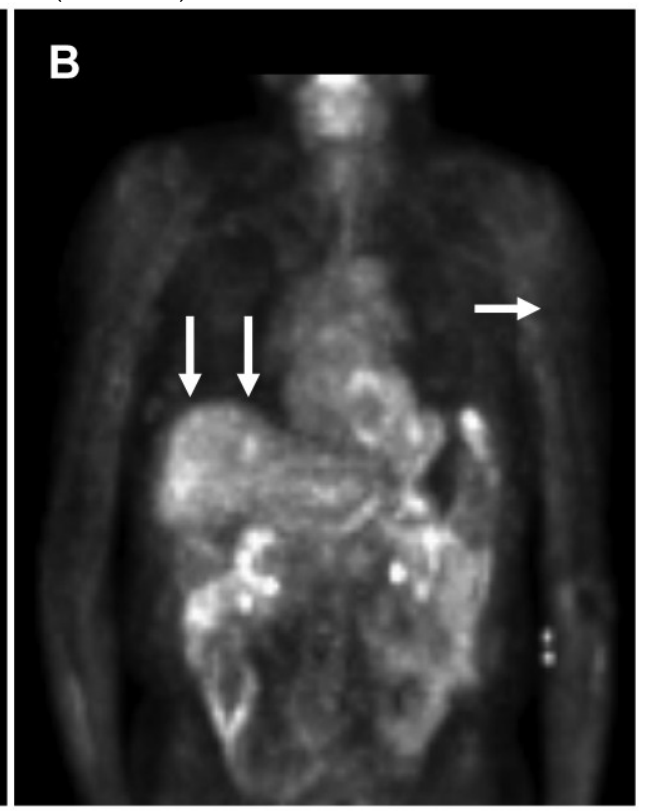

Figure 2. PET scan demonstrates tumor improvement while on liposomal doxorubicin treatment. A. Patient's PET scan prior to liposomal doxorubicin, and B. Patient's PET scan after 16 cycles (I cycle $=3$ weeks) of liposomal doxorubicin demonstrated shrinkage of tumor with treatment. Note the significant improvement in liver lesions as well as a left upper extremity skin lesion. Arrows indicate tumor lesions with notable reduction with treatment. In the central liver in the region of the caudate lobe there is a lesion which was present on 10/18/05 but no longer seen on 10/23/06 [Standardized Uptake Values (SUV) 10/18/05: Average 6.4, Max 8.3. 10/23/06: Average 2.I, Max 2.6]. In the periphery of the anterior segment of the right lobe there is a lesion which was large on I0/I8/05 and much smaller on 10/23/06 [SUV I0/I8/05: Average 3.2, Max 4.4. 10/23/06: Average 3.0, Max 3.5]. 
Table 3. May 2008: Upregulated genes, proteins, and matching FDA approved drugs identified from liver biopsy of ACC tumor.

\begin{tabular}{|c|c|c|}
\hline Protein & $\begin{array}{l}\text { IHC Intensity/\% cells } \\
\text { staining positive }\end{array}$ & Posible Interacting agent \\
\hline PR & $+2 / 60 \%$ & $\begin{array}{l}\text { Exemestane, fulvestrant, gonadorelin, goserelin, } \\
\text { medroxyprogesterone, megestrol, tamoxifen, torem- } \\
\text { ifene }\end{array}$ \\
\hline SPARC & $+2 / 60 \%$ & Paclitaxel albumin-bound \\
\hline EGFR & $+2 / 60 \%$ & $\begin{array}{l}\text { Lapatinib, erlotinib, getifinib, cetuximab, pani- } \\
\text { tumumab, dasatinib }\end{array}$ \\
\hline PDGFR & $+2 / 50 \%$ & Imatinib, sorafenib, sunitinib \\
\hline TOP2A & $+2 / 30 \%$ & $\begin{array}{l}\text { Doxorubicin, epirubicin, etoposide, mitoxantrone, } \\
\text { teniposide }\end{array}$ \\
\hline HSP90 & $+2 / 30 \%$ & CNF2024, 17-AAG \\
\hline c-kit & $+1 / 40 \%$ & Imatinib \\
\hline P-glycoprotein & $+2 / 30 \%$ & Ixabepilone \\
\hline Gene & Fold Increase & Possible Interacting Agent \\
\hline TOP2A & 90.92 & $\begin{array}{l}\text { Doxorubicin, epirubicin, etoposide, mitoxantrone, } \\
\text { teniposide }\end{array}$ \\
\hline GART & 3.72 & Pemetrexed \\
\hline ADA & 2.72 & Cytarabine, pentostatin \\
\hline HSP90AA1 & 2.57 & CNF2024 \\
\hline SPARC & 2.53 & Paclitaxel albumin-bound \\
\hline TOP1 & 2.52 & Irinotecan, topotecan \\
\hline YES1 & 2.08 & dasatinib \\
\hline HIF1A & 1.80 & Sorafanib, sunitinib, bevacizumab \\
\hline Drug resistant Genes/Proteins & $\begin{array}{l}\text { Fold Increase or IHC } \\
\text { positivity }\end{array}$ & Drug resistance \\
\hline TYMS & 15.81 & Capecitabine and fluorouracil \\
\hline DHFR & 5.34 & Methotrexate \\
\hline P-glycoprotein & $+2 / 30 \%$ & $\begin{array}{l}\text { Paclitaxel, doxorubicin, etoposide, epirubicin, docet- } \\
\text { axel, vinblastine, vinorelbine, topotecan, teniposide }\end{array}$ \\
\hline
\end{tabular}

ERCC1 over-expression raises the possibility of resistance to carboplatin, cisplatin and oxaliplatin. DHFR was over-expressed raising the possibility of resistance to methotrexate. TYMS was over-expressed 15.81-fold showing a possible resistance to capecitabine and fluorouracil. Other proteins examined by IHC that were negative include Her2/neu, ER, androgen receptor (AR), CD52, CD25 and survivin. As well, gene array data revealed upregulation of a number of new gene targets not identified in the profile performed 3 years previously in May 2005 (Table 3 ). These genes are Topoisomerase II (TOP2), phosphoribosylglycinamide formyltransferase (GART), adenosine deaminase (ADA), heat shock protein 90kDa alpha class A member 1 (HSP90AA1), SPARC, topoisomerase I (TOP1), v-yes-1 Yamaguchi sarcoma viral oncogene homolog 1 (YES) and hypoxia inducible factor 1 alpha (HIF1A).

Primary cells were established in cell culture from the lymph node metastasis (Panc-4). These cells were tested with some of the drugs listed in Table 3.
Lipase levels measured in the media of confluent Panc- 4 cells exchanged at 48 hours was $137 \mathrm{U} / \mathrm{L}$. The control media measured $1 \mathrm{U} / \mathrm{L}$, thus validating that both lesions were pancreatic acinar cell carcinoma. As shown in Figure 3A, Panc-4 cells were tested for growth inhibition using lapatinib, ixabepilone or the combination of the two together. Monotherapy results in a dose responsive decrease in cell number as the concentration of each drug is increased. Using a fixed ratio of the two drugs at or above the IC50s for each compound, synergy was demonstrated (Figure 3A). The calculated CI values were 0.44 for $500 \mathrm{nM}: 2 \mathrm{nM}$ concentrations of lapatinib:ixabepilone, 0.43 for the 1 $\mu \mathrm{M}: 4.0 \mathrm{nM}$ doses and 0.45 for the $2000 \mathrm{nM}: 16 \mathrm{nM}$ doses. In Figure 3B, Lapatinib and dasatinib (src inhibitor) were tested alone and together for antitumor synergy in Panc-4 cells and found to be synergistic in the median dose ranges $(0.1 \mu \mathrm{M}: 10 \mathrm{nM}, 2 \mu \mathrm{M}: 20 \mathrm{nM} \&$ $3 \mu \mathrm{M}: 30 \mathrm{nM}$ ) with CI values of $0.72,0.78$ and 0.94 respectively (Figure 3B). The proteosome inhibitor, bortezomib, was examined in combination at a fixed 
ratio of 100:1 (bortezomib:17-AAG) with the hsp90 inhibitor, 17-AAG (Figure 3C). Synergy was demonstrated at higher concentrations with the $650 \mathrm{nM}$ 17-AAG:6.5 nM bortezomib doses demonstrating a CI value of 0.84 while $800 \mathrm{nM}: 8 \mathrm{nM}$ doses yielded CI value of 0.75 and the $1000 \mathrm{nM}: 10 \mathrm{nM}$ doses yielding a CI value of 0.67 .
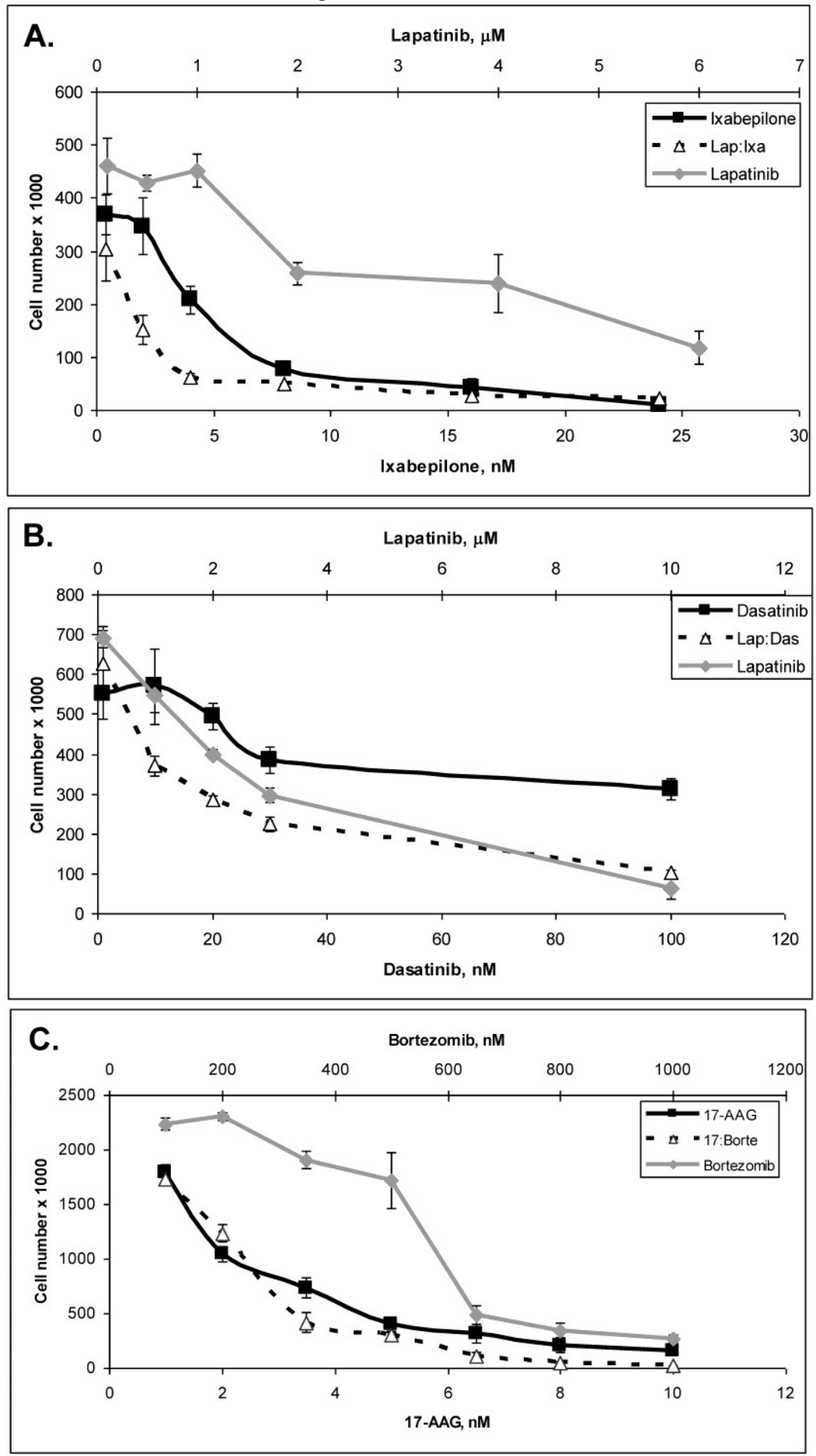

Figure 3. ACC Lymph node metastatic tumor cells respond to drug therapies and demonstrate antitumor synergy in combination. A. Panc-4 cells were plated at $2 \times 10^{4}$ cells $/ \mathrm{ml}$ in I2-well plates and treated the following day with lapatinib, ixabepilone or both at the indicated concentrations. Cell number was calculated and combinatorial drug synergy determined as described in Materials and Methods. B. Panc-4 were treated with lapatinib and/or dasatinib at the indicated doses and examined for drug synergy as described above. C. Panc-4 were treated with bortezomib and/or I7-AAG at the indicated doses and examined for drug synergy as described above. 
Table 4. Serum lipase levels from ACC tumor grown in athymic nude mice.

\begin{tabular}{llll}
\hline Tumor & $\begin{array}{l}\text { Implant date/ } \\
\text { harvest date }\end{array}$ & $\begin{array}{l}\text { Tumor volume } \\
\left(\mathrm{mm}^{3}\right)\end{array}$ & $\begin{array}{l}\text { Lipase levels (U/L) } \\
\text { (low limit of detection }=3 \\
\text { U/L) }\end{array}$ \\
\hline Panc 4 & $4 / 25 / 08-12 / 18 / 08$ & 180 & Blood not drawn \\
$*$ Panc $4-1$ & $12 / 18 / 08-6 / 26 / 2009$ & 745 & 811 \\
*Panc $4-2$ & $10 / 2 / 09-4 / 22 / 10$ & 210 & 188 \\
*Panc 4-3 & $1 / 8 / 10-4 / 22 / 10$ & 920 & 1731 \\
\hline
\end{tabular}

*-Successive passage of tumor from the preceding tumor.

An in vivo model was also established, whereby tumor tissue was implanted directly into athymic nude mice subcutaneously into the right hind flank. This was indicative that the biopsied metastatic tumor lesions had become more aggressive when compared to the previous biopsy in May 2005 which did not establish tumors when implanted into mice. These tumors have been passaged continuously now for over two years and continue to secrete lipase into the blood (Table 4). Cumulatively the genomic, IHC and cell models are indicative that the tumor had progressed to a more aggressive phenotype from the previously biopsied tumor tissue.

In July 2008, there was progression of liver lesions and development of mesenteric lesions. He was started on sorafenib (tyrosine kinase inhibitor) and temozolomide (alkylating agent) until progression November 2008. He received external beam radiation to a progressive liver lesion in November 2008. As indicated in Table 1, lipase levels are shown during this period of treatment between July to November 2008.

His hepatic and mesenteric disease had worsened by January 2009 so he was initiated on albumin-bound paclitaxel (Abraxane) $100 \mathrm{mg} / \mathrm{m}^{2}$ and bevacizumab $5 \mathrm{mg} / \mathrm{kg}$. Despite improvement in his serum lipase levels (Table 1), albumin-bound paclitaxel was discontinued after two doses due to progressive neuropathy. Bevacizumab was discontinued after three doses due to progressive confusion and further therapy was declined. The patient expired in July 2009 from complications related to progression of metastatic ACC.

\section{Discussion}

A multi-disciplinary approach, with the concerted efforts of surgeons, interventional radiologists, radiation oncologists, medical oncologists, as well as the efforts of basic scientists working with the pa- tient's cell line was associated with an 8 year survival of this patient. Moreover, the patient enjoyed a very good quality of life with his treatments as well, maintaining his very active lifestyle until shortly before his death.

How does our patient's experience compare with others? Like the established literature showing male predominance and younger age at presentation ${ }^{8}$, our patient was a male in his early 60 's at the time of diagnosis. Also consistent with the literature, our patient had better survival time than would be expected with a pancreatic adenocarcinoma. Table 5 provides a brief summary of ACC patient characteristics from a few retrospective studies. A review of the Mayo Clinic Tumor Registry has shown 42 patients diagnosed with ACC from 1972 through 2009. A male predominance and younger age at diagnosis was observed in the Mayo Clinic series (Table 5).

As mentioned, case reports and retrospective reviews do show extended survival in many patients with resectable disease, and in some with metastatic disease at presentation. Although published reports are few, survival beyond a few months in patients with metastatic disease is noted in patients managed with localized procedures such as metastasectomies. Chemotherapies such as 5-fluorouracil, capecitabine, or gemcitabine combined with radiation have been used with some success $2,7,18,21$. Case reports of metastatic patients managed with systemic treatments show mixed responses to treatment ${ }^{17-26}$. Considered the standard of care for pancreatic adenocarcinoma, palliative treatment with gemcitabine, either alone or as combination therapy, has shown benefit in some reports but disappointing in others ${ }^{17,22,24,25}$. Some activity has been noted with 5-fluorouracil2, 19 and paclitaxel (present study23). Because of the small number of cases, it is difficult to draw definitive conclusions regarding the best approach to systemic therapy. 
Table 5. Retrospective review of patients diagnosed with ACC.

\begin{tabular}{|c|c|c|c|c|c|}
\hline Study & $\begin{array}{l}\text { Patient Num- } \\
\text { ber, } \% \text { male }\end{array}$ & $\begin{array}{l}\text { Median } \\
\text { Age }\end{array}$ & $\begin{array}{l}\text { Median Sur- } \\
\text { vival (months) }\end{array}$ & Median Tumor size & $\begin{array}{l}\text { Metastasis } \\
\text { diagnosis }\end{array}$ \\
\hline Mayo Clinic & $42,64 \%$ & 59.5 & $\begin{array}{l}\text { Data not } \\
\text { available }\end{array}$ & Data not available & $37.5 \%$ \\
\hline Klimstra DS, et al. ${ }^{1}$ & $28,86 \%$ & 62 (mean) & 18.1 (mean) & $10.8 \mathrm{~cm}$ (mean) & $50 \%$ \\
\hline Holen $\mathrm{KH}$, et al. ${ }^{2}$ & $39,77 \%$ & 60 & 19 & Data not available & $49 \%$ \\
\hline Kitagami $\mathrm{H}$, et al. ${ }^{3}$ & $115,67 \%$ & 59.6 (mean) & 41 & Data not available & $28.7 \%$ \\
\hline Wisnoski NC, et al. ${ }^{8}$ & $672,54 \%$ & 56.7 (mean) & 47 & Data not available & $53.1 \%$ \\
\hline Seth AK, et al. ${ }^{7}$ & $14,36 \%$ & 57 & 33 & $3.9 \mathrm{~cm}$ & $14.3 \%$ \\
\hline Matos JM, et al. ${ }^{5}$ & 17 & 59 & 19 & $5.3 \mathrm{~cm}$ & $17.6 \%$ \\
\hline
\end{tabular}

Why did our patient, unlike the vast majority of ACC patients metastatic at presentation, have such a prolonged survival? We believe there were two major contributing factors. Like previously described reports, our patient benefitted from an aggressive multi-disciplinary approach, with surgical management of his primary tumor and localized interventions for his metastases. Also like previous reports, disease control with empiric systemic treatments was attempted, with mixed results. However, we believe the second major contributing factor was moving beyond empiric systemic treatment approaches to systemic therapies based on translational studies performed on the patient's own tumor cell line derived from his metastatic tumor tissues. Utilizing the patient's own tumor cells takes into account specific genomic and epigenetic alterations that will modify response to therapy. Utilizing this approach combined with genomics and proteomics, drugs may be identified and tailored as combinatorial therapy leading to individualized medicine. Because of these studies, doxorubicin was selected and offered a dramatic and durable response. To our knowledge this is the first report of doxorubicin being used for ACC. Doxorubicin does not have a role in the management of pancreatic adenocarcinoma. Whether the success of doxorubicin in our patient could be extrapolated to ACC in general or whether its success is specific to our patient in particular is of course not known. Also we should note, as can be expected, the correlation between cell line response and patient response is not perfect, as is demonstrated by our patient's mixed and only transient response to imatinib. Although not perfect, the combined genomics, proteomics and drug testing in the patient's cells over time demonstrated that this ACC tumor evolved at the gene and protein level into a more aggressive tumor with multiple enhanced oncogenic signaling pathways being turned on.

This case demonstrates the possibility of extended survival of approximately 8 years after the diagnosis of metastatic acinar cell carcinoma of the pancreas with an aggressive multi-modality therapeutic approach (surgical, radiation and systemic treatments) directed by genomic profiling of the patient's tumor identifying druggable gene alterations coupled with demonstrating antiproliferative activity in the patient's own tumor cell line in response to the identified molecular therapeutics. The extended survival was feasible by the observed excellent responses obtained by tailoring treatment based on in vitro cell culture responses to imatinib and liposomal doxorubicin of the patient's tumor cells. A translational strategy, from bench to bedside, may lead to improved outcomes for individual patients with less common malignancies, where there may be a paucity of evidence-based, prospective data to otherwise guide management.

\section{Conflict of Interest}

Daniel D. von Hoff, MD, FACP serves as a Consultant and Executive Director, Caris Life Sciences Clinical Research. The other authors have declared that no conflict of interest exists.

\section{References}

1. Klimstra DS, Heffess CS, Oertel JE, Rosai J. Acinar cell carcinoma of the pancreas. A clinicopathologic study of 28 cases. Am J Surg Pathol. 1992;16(9):815-837.

2. Holen KD, Klimstra DS, Hummer A, et al. Clinical characteristics and outcomes from an institutional series of acinar cell carcinoma of the pancreas and related tumors. J Clin Oncol. 15 2002;20(24):4673-4678.

3. Kitagami H, Kondo S, Hirano S, Kawakami H, Egawa S, Tanaka M. Acinar cell carcinoma of the pancreas: clinical analysis of 115 patients from Pancreatic Cancer Registry of Japan Pancreas Society. Pancreas. 2007;35(1):42-46.

4. Mansfield A, Tafur A, Smithedajkul P, Corsini M, Quevedo F, Miller R. Mayo Clinic experience with very rare exocrine pancreatic neoplasms. Pancreas. 2010;39(7):972-975.

5. Matos JM, Schmidt CM, Turrini O, et al. Pancreatic acinar cell carcinoma: a multi-institutional study. J Gastrointest Surg. 2009;13(8):1495-1502.

6. Schmidt CM, Matos JM, Bentrem DJ, Talamonti MS, Lillemoe $\mathrm{KD}$, Bilimoria KY. Acinar cell carcinoma of the pancreas in the 
United States: prognostic factors and comparison to ductal adenocarcinoma. J Gastrointest Surg. 2008;12(12):2078-2086.

7. Seth AK, Argani P, Campbell KA, et al. Acinar cell carcinoma of the pancreas: an institutional series of resected patients and review of the current literature. J Gastrointest Surg. 2008;12(6):1061-1067.

8. Wisnoski NC, Townsend CMJr., Nealon WH, Freeman JL, Riall TS. 672 patients with acinar cell carcinoma of the pancreas: a population-based comparison to pancreatic adenocarcinoma. Surgery. 2008;144(2):141-148.

9. Bogart MM, Milliken MC, Patterson JW, Padgett JK. Pancreatic panniculitis associated with acinic cell adenocarcinoma: a case report and review of the literature. Cutis. 2007;80(4):289-294.

10. Hashimoto M, Miki K, Beck Y, Kokudo N, Makuuchi M, Tanaka $\mathrm{H}$. Femoral neck fracture as a complication of lipase-secreting pancreatic acinar cell carcinoma. Surgery. 2007;142(5):779-780.

11. Kuerer $H$, Shim $H$, Pertsemlidis D, Unger P. Functioning pancreatic acinar cell carcinoma: immunohistochemical and ultrastructural analyses. Am J Clin Oncol. 1997;20(1):101-107.

12. Martin SK, Agarwal G, Lynch GR. Subcutaneous fat necrosis as the presenting feature of a pancreatic carcinoma: the challenge of differentiating endocrine and acinar pancreatic neoplasms. Pancreas. 2009;38(2):219-222.

13. Ohno Y, Le Pavoux A, Saeki H, Asahina A, Tamaki K. A case of subcutaneous nodular fat necrosis with lipase-secreting acinar cell carcinoma. Int J Dermatol. 2003;42(5):384-385.

14. Poelman SM, Nguyen K. Pancreatic panniculitis associated with acinar cell pancreatic carcinoma. J Cutan Med Surg. 2008;12(1):38-42.

15. Radin DR, Colletti PM, Forrester DM, Tang WW. Pancreatic acinar cell carcinoma with subcutaneous and intraosseous fat necrosis. Radiology. 1986;158(1):67-68.

16. Robertson JC, Eeles GH. Syndrome associated with pancreatic acinar cell carcinoma. Br Med J. 20 1970;2(5711):708-709.

17. Antoine $M$, Khitrik-Palchuk M, Saif MW. Long-term survival in a patient with acinar cell carcinoma of pancreas. A case report and review of literature. JOP. 2007;8(6):783-789.

18. Chen $\mathrm{CP}, \mathrm{Chao} \mathrm{Y}, \mathrm{Li} \mathrm{CP}$, et al. Concurrent chemoradiation is effective in the treatment of alpha-fetoprotein-producing acinar cell carcinoma of the pancreas: report of a case. Pancreas. 2001;22(3):326-329.

19. Distler M, Ruckert F, Dittert DD, et al. Curative resection of a primarily unresectable acinar cell carcinoma of the pancreas after chemotherapy. World J Surg Oncol. 2009;7:22.

20. Kobayashi S, Ishikawa $\mathrm{O}$, Ohigashi $\mathrm{H}$, et al. Acinar cell carcinoma of the pancreas successfully treated by en bloc resection and intraperitoneal chemotherapy for peritoneal relapse: a case report of a 15-year survivor. Pancreas. 2001;23(1):109-112.

21. Lee JL, Kim TW, Chang HM, et al. Locally advanced acinar cell carcinoma of the pancreas successfully treated by capecitabine and concurrent radiotherapy: report of two cases. Pancreas. 2003;27(1):e18-22.

22. Mueller SB, Micke O, Herbst H, Schaefer U, Willich N. Alpha-fetoprotein-positive carcinoma of the pancreas: a case report. Anticancer Res. 2005;25(3A):1671-1674.

23. Riechelmann RP, Hoff PM, Moron RA, da Camera Lopes LH, Buzaid AC. Acinar cell carcinoma of the pancreas. Int $J$ Gastrointest Cancer. 2003;34(2-3):67-72.

24. Seki Y, Okusaka T, Ikeda M, Morizane C, Ueno H. Four cases of pancreatic acinar cell carcinoma treated with gemcitabine or S-1 as a single agent. Jpn J Clin Oncol. 2009;39(11):751-755.

25. Sorscher SM. Metastatic acinar cell carcinoma of the pancreas responding to gemcitabine, 5-fluorouracil and leucovorin therapy: a case report. Eur J Cancer Care (Engl). 2009;18(3):318-319.
26. Suzuki A, Sakaguchi T, Morita Y, et al. Long-term survival after a repetitive surgical approach in a patient with acinar cell carcinoma of the pancreas and recurrent liver metastases: report of a case. Surg Today. 2010;40(7):679-683. 